\title{
The Reasons of University Students for Selecting Sexual Health Course
}

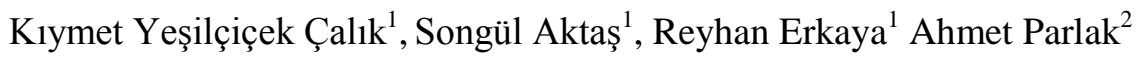 \\ ${ }^{1}$ Karadeniz Technical University Faculty of Health Science, Obstetrics and Gynaecology Nursing Department, Trabzon, Turkey. \\ ${ }^{2}$ Karadeniz Technical University Faculty of Health Sciences Nursing Department student, Trabzon.
}

Received: 01 June 2015 accepted: 10 August 2015/ published online: 30 August 2015

(C) Ordu University Institute of Health Science, Turkey, 2015

\begin{abstract}
Objective: The research was conducted to determine the reasons of university students taking "Sexual Health" course for choosing it.

Methods: The study was conducted at Karadeniz Technical University, Trabzon, Turkey. The research population consisted of all 64 sophomore students (10 male, 54 female) studying at Karadeniz Technical University, Faculty of Health Sciences Department of Nursing and taking "Sexual Health" lesson as an elective course. Developed by researchers, "Feedback Form on the Sexual Health Course" was used as a data collection tool. Data were analyzed using the number and percentage values.

Results: The findings indicate that the majority of the students had insufficient knowledge about sexual health (93.8\%), wanted to get information about everything related to sexual health (35.9\%), chose the course to be informed about sexuality and reproductive health $(45.4 \%)$, hadn't received sexual health training before $(58.7 \%)$, wanted education on sexual health (100\%), wanted sexual health course to be 'compulsory' (96.9\%) and should be given at secondary level (50.0\%) and generalized across the country (96.9\%).

Conclusion: The research findings were discussed in the light of relevant literature emphasizing the importance of sexual health course for university students and referring to the requirement of the comprehensive sexual health education.

Key words: Sexual health course, university students, sexual health education, nursing.

Address for correspondence/reprints:

Kıymet Yeşilçicek Çalık

Business telephone number: +90462 2300476-8865

Fax number: +90 4622300475

E-mail: kyesilcicek@ktu.edu.tr

omrumyesilcicek@hotmail.com

*This research submitted as a oral presentation to the 13 th National Congress of Nursing Students, 1-3 May, 2014, Trabzon, Turkey.

DOI: $10.19127 /$ mbsjohs.68309

\section{Introduction}

The period of youth is a period in which an individual gain social maturity, reach a level where he/she can make his/her own decisions, can act independently and establish a healthy relationship with the opposite sex (CETAD, 2006). During this period, since they cannot think over the results of the events thoroughly young people can easily exhibit risk taking behaviors (HÜKSAM, 2002), therefore increasingly face with risks such as sexual intercourse at an early age, early marriage, sexually transmitted diseases (STDs), unwanted or early pregnancy, and childbirth complications and remain vulnerable.
\end{abstract}


Also during this period, the lack of efficient distribution of information regarding health needs of young people lead them to tend towards risky behaviors (Alpua, 2006). Yet in the General Assembly of World Sexual Health Union in Sydney in 2007 and in Development plans, the requirement of young people's being informed about sexuality and health issues and providing universal access to information in order not to face any possible problems that might adversely affect their overall well-being are clearly indicated (Bozdemir and Özcan, 2011).

However, implementations show that sex education is not included in the education system and has very limited space in other courses (Çalışandemir et al., 2008; Çok and Kutlu, 2010). Existing health facilities are not sufficient enough for young people in terms of sexual health information, consultancy and service delivery (Nalbant and Bulut, 2001). Moreover, the fact that their families have not received formal education about sexual education, feel shy to talk about it and perceive sexuality as a taboo causes inability to talk about sexual issues comfortably (Gölbaşı, 2005; Pinar et al., 2009; Erbil et al., 2010; Bozdemir and Özcan, 2011). However, during the period of youth, also known as gender identity development period, young people are known to be in need of getting accurate and reliable information about sexual health (Biri et al., 2007). Because, the young develop their values related to sexuality and make decisions regarding their sexual behavior in the process of becoming adults (Civil and Yildiz, 2010). That is why training in sexual matters will contribute individuals to organize their sexual life consciously, develop positive attitudes and values towards sexuality in growth and maturing process and make smarter choices in sexual behavior (Güler and Yöntem, 2007). Studies suggest that young people have a low level of knowledge about sexual health, generally get information about sexuality from their friends and the internet, parents cannot give enough information because of feeling uncomfortable to talk about sexual matters and they have not received any training on sexual health issues and want to receive information (Gökengin et al., 2003; Hazır -B1kmaz and Güler, 2007; Çetin et al., 2008; Siyez, 2009; Topkaya and Sümer, 2010, Civil and Y1ldı, 2010) To protect nursing students' own sexual health and enable them to provide guidance on this issue for healthy or sick individuals in their professional life will be possible with the scientific knowledge and skills they have acquired from reliable sources. Based on this need, it was aimed to determine and evaluate the reasons of nursing students at Faculty of Health Sciences Department, Karadeniz Technical University for choosing the sexual health course.

\section{Materials and Methods}

Type of research

This study is a descriptive research.

Population and sample

The population of the research consisted of all sophomore students (64) studying at the Faculty of Health Sciences Department of Nursing, Karadeniz Technical University in the spring semester, 20132014 academic year and taking "Sexual Health" course as an elective lesson. Election was not made in the study sample, all the students [10 male (15.6\%), 54 females (84.4\%)] were reached.

\section{Data Collection Tool}

As the data collection tool 'Feedback Form on Sexual Health Course' developed by the researchers through literature review was used. A group of 10 students taking Sexual Health course was applied a preliminary study at the end of the lesson in order to control the clarity of the form. Preliminary application forms were finalized after the necessary arrangements by asking expert opinion in the field. In the form, there are a total of 30 questions consisting of closed and open-ended questions to assess students' feedback about the course.

Feedback Form on Sexual Health Lesson

In developing the form, we benefit from the following publications: Hacettepe University Women's Problems Research and Application Center, the project of investigating the factors affecting the adolescents and youth's sexual / reproductive health in Turkey, HÜKSAM (2002), the World Health Organization-WHO (2011), Youth and health risks report, Sexual Education Treatment and Research Association-CETAD (2006), the national and advocacy project in the field of sexual and reproductive health through local media, Acknowledgement File 1 and CETAD (2007), "Youth and Sexuality" file, the issue that young people talk least but are concerned most: Sexuality. Furthermore, other studies' data collection tools the aims of which overlap with this study were also taken into account. For face and content validity, three experts' opinions were taken and the form was finalized in accordance with their feedback. 


\section{Data Collection}

Research data were collected after obtaining written permission from the administration of the Faculty and verbal consent from the students. Before handing out the forms, the aim of the study was explained to students in the classroom by the researchers and voluntary students completed the form 15-20 minutes.

\section{Ethical statement}

Before the study could begin, permission was obtained from the institution, and the participants were then invited to participate in the study. They were also informed by the researchers and through an approval protocol that they would not be paid for their participation. The researchers guaranteed participants that their identities and answers would be kept confidential. The study conformed to the principles of the Declaration of Helsinki.

\section{Data Analysis}

Data were analyzed using SPSS 17.0 software package. The frequencies and percentages of the data obtained from 'Feedback Form on the Sexual Health Course' developed in order to determine students' views on the sexual health course were calculated.

\section{Research Limitations}

The fact that the results only represent the institution where the study was conducted and the views of the students in nursing department taking sexual health course was accepted as the limitation of the study.

\section{Results}

$84.4 \%$ of the students involved in our study were female, $15.6 \%$ were male, mean age: $20.0 \pm$ 1.13 years, $89.1 \%$ had nuclear family, $59.4 \%$ graduated from high school, $56.2 \%$ spent most of their life in Black sea region. The fathers (35.9\%) and the mothers $(68.8 \%)$ of the students are high school and primary school graduates respectively.

When Table 1 is examined, it is seen that students' median age of receiving first information on sexual health issues is 14:00 \pm 1.85 (Min: 10.00 Max: 18:00). 81.3\% learned information about sexual health from their friends, $93.8 \%$ do not have sufficient information about sexual health and $35.9 \%$ want to learn everything related to sexual health (Table 1).
Table 1. Students' sexual health information resources and information needs

\begin{tabular}{lcc}
\hline & Number & $\%$ \\
\hline $\begin{array}{l}\text { The median age of receiving } \\
\text { first information about sexual } \\
\text { health issues. }\end{array}$ & $\begin{array}{c}\text { (Min: } 10.00,1.85 \\
\text { Max: } 18.00)\end{array}$ \\
\hline Information resources on & & \\
sexual health* & & \\
Friend & 52 & $\mathbf{8 1 . 3}$ \\
Media & 47 & 73.4 \\
Mother & 23 & 35.9 \\
Sister & 8 & 12.5 \\
Family elder & 4 & 6.3 \\
Films & 3 & 4.7 \\
Brother & 2 & 3.1 \\
Father & 2 & 3.1 \\
\hline Do you have sufficient & & \\
information about sexual & & \\
health? & & \\
Yes & 4 & 6.2 \\
No & 60 & $\mathbf{9 3 . 8}$ \\
\hline Sexual health issues that you & & \\
want to get information on & & \\
About everything & 23 & $\mathbf{3 5 . 9}$ \\
About healthy sexual & & \\
relationships & 20 & 31.3 \\
About sexually transmitted & & \\
diseases & 9 & 14.1 \\
About what sexuality means & 3 & 4.7 \\
About family planning & 2 & \\
About maternal and child & & \\
health & & \\
I have no idea & 5 & \\
\hline & & \\
\hline
\end{tabular}

*More than one answer was given and percentages were calculated based on $n$

When Table 2 is examined, it is seen that $58.7 \%$ of the students did not receive education about sexual health, all the students (100.0\%) want education on sexual health, 50.0\% think sexual health education should be given starting from the secondary school, $96.9 \%$ state that sexual health education should be compulsory, $46.9 \%$ express that it would be more appropriate to give the education separately to girls and boys and $96.9 \%$ point out that sexual health education should be widely launched at schools (Table 2). 
Table 2. Students' views regarding sexual health education

\begin{tabular}{lrr}
\hline Views & Number & $\%$ \\
\hline Have you received information & & \\
on sexual health? & 27 & 41.3 \\
Yes & 37 & $\mathbf{5 8 . 7}$ \\
No & & \\
Should education be given on & \\
sexual health? & 64 & $\mathbf{1 0 0 . 0}$ \\
Yes & - & - \\
No & & \\
When should education be given & & \\
on sexual health? & 13 & 20.3 \\
As of primary school & 32 & $\mathbf{5 0 . 0}$ \\
As of secondary school & 9 & 14.1 \\
At high School & 3 & 4.7 \\
Before getting married & 4 & 6.3 \\
At university & 3 & 4.7 \\
It does not matter & & \\
Should sexual health course be & \\
compulsory or elective? & 62 & $\mathbf{9 6 . 9}$ \\
Compulsory & 2 & 3.1 \\
\hline Elective & & \\
Should sexual health course be & & \\
given to girls and boys together & & \\
or separately? & & \\
Separately & & \\
Together & 30 & $\mathbf{4 6 . 9}$ \\
Elective & 25 & 39.1 \\
Should sexual health course start & & 14.1 \\
at school? & & \\
Yes & & \\
No & & \\
\hline
\end{tabular}

Table 3. Reasons of students for selecting sexual health course

\begin{tabular}{|c|c|c|}
\hline $\begin{array}{l}\text { Reasons of Selecting Sexual Health } \\
\text { Course* }\end{array}$ & Number & $\%$ \\
\hline $\begin{array}{l}\text { To have knowledge about sexuality and } \\
\text { reproductive health }\end{array}$ & 29 & 45.4 \\
\hline $\begin{array}{l}\text { To correct the wrong things that I know } \\
\text { to be true }\end{array}$ & 18 & 28.1 \\
\hline To inform the people around me & 15 & 23.4 \\
\hline $\begin{array}{l}\text { Because it is a compulsory elective } \\
\text { course }\end{array}$ & 11 & 17.2 \\
\hline $\begin{array}{l}\text { To create infrastructure for obstetrics } \\
\text { course }\end{array}$ & 11 & 17.2 \\
\hline $\begin{array}{l}\text { To protect my sexual health and apply to } \\
\text { my life }\end{array}$ & 7 & 10.9 \\
\hline $\begin{array}{l}\text { To be able to answer the questions my } \\
\text { friends and people around me ask }\end{array}$ & 4 & 6.3 \\
\hline $\begin{array}{l}\text { To be able speak up and correct the } \\
\text { wrong things spoken secretly }\end{array}$ & 2 & 3.1 \\
\hline To learn pregnancy prevention methods & 2 & 3.1 \\
\hline Because I wonder sexual health issues & 2 & 3.1 \\
\hline $\begin{array}{l}\text { To learn how to troubleshoot issues } \\
\text { related to sexuality }\end{array}$ & 1 & 1.6 \\
\hline \multicolumn{3}{|l|}{$\begin{array}{l}\text { The status of sexual health course to } \\
\text { meet expectations }\end{array}$} \\
\hline Yes & 60 & 93.8 \\
\hline No & 4 & 6.2 \\
\hline
\end{tabular}

When Table 3 is examined, it is understood that $45.4 \%$ of students chose sexual health course "to have information about sexual and reproductive health" and $93.8 \%$ expressed that it met their expectations (Table 3 ).

\section{Discussion}

This research was conducted to assess the reasons of sophomore students studying at Nursing Department for choosing "Sexual Health" course. In general, research findings indicate that students' main sources of information about sexual health are their friends and media. Moreover, fathers, brothers and films were expressed as minimum information sources referred by students. Similarly in Esgin's (2000) study, it is stated that $82 \%$ of young people can speak about sexuality most comfortably with their friends from their own gender. In the other studies carried out in Turkey it is observed that basic information sources of young people about the issue are friends, books, television, the internet, newspapers and families respectively (Karabulutlu and K1lıç, 2011; Atan Ünsal et al., 2012; Kumcağız et al., 2013). Since sexuality issues are perceived as "shame and sin" especially in developing countries like Turkey, young people can speak about such issues more freely with friends because families carry on their traditional attitude asserting that sexuality is "intimate" and prefer not to talk about it with their children. Thus, young people consult the sources outside school to meet their information needs regarding sexual and reproductive health and are often informed incorrectly (HÜKSAM, 2002; Çalışandemir et al., 2008).

In our study it was found out that students do not have sufficient information about sexual health and want to learn everything related to it. Studies suggest that young people do not have enough information especially about sexuality, reproductive physiology, pregnancy prevention or CYBH but are willing to get information and education on these issues (HÜKSAM, 2002; CETAD, 2006). In their study Kadığlu et al. (2008) investigated students' views on sexuality and sexual education suggests that $61.0 \%$ of them found the information about the sexuality slightly enough. Blum and Nelson (2004) indicated that two-thirds of female and male students had no sufficient information about sexuality. 
The research findings on information needs reveal that students want to improve themselves more on sexuality and sexual health issues.

In our study, the ratio of the students stating they had not received sexual health education so far and considered sexual health education should start widely at secondary schools is quite high and this was assessed as a notable finding. Today, information on sexuality and reproduction are taught as compulsory or elective courses in university curriculums starting from primary schools in many Western countries. In Turkey, it is emphasized that primary school years is a crucial period for gaining knowledge, skills and attitudes about sexuality by indicating that the highest enrollment rate $(92 \%)$ is during primary school period (B1kmaz and Güler, 2007). But today in our country sexual health education is still not included in the formal education system (HÜKSAM, 2002; Çok and Kutlu 2010). It is known that, on the basis of this, there lies a concern about sexual health education would lead young people to wrong sexual intercourse and in the early stages (Nicolle et al., 1999; Gürsoy and Gençalp, 2010). However, research shows that these concerns are needless. According to Y1ldirımkaya, in a survey of with 317 thousand people in 41 countries around the world, $98 \%$ of participants stated young people should receive sexual education at schools before the age of 16 (Gürsoy and Gençalp, 2010).

The research findings by CETAD (2006) with 1537 people in 20 cities in seven regions reveal that $75 \%$ of the population is willing to give sexual education at schools. Likewise, according to a study conducted at Marmara University campus with 3665 students, $76.5 \%$ of students stated that they should be given sexual health education at schools (Aydoğan, 2001). The study carried out with 519 teachers working at primary schools in Adana showed that the ratio of the participants supporting sexual education course at schools was $97.5 \%$. (Akbaş, 2000). These findings are consistent with the other research findings (Pinar et al., 2009; Dağ et al., 2012; Kumcağız et al., 2013). Students must be supported on sexual health by giving them education on these issues so that they can access accurate information on sexual matters, make right decisions primarily about themselves and behave professionally away from wrong judgments (Tokuç et al., 2011).
The most effective, cheapest and accessible way of this is to integrate sexual health education into mainstream school curriculum (Gürsoy and Gençalp, 2010). Another remarkable finding of this study is the students' view about the appropriateness of giving sexual health education to girls and boys separately. Considering the study regarding sex education at the national level, it is seen that in the continuation of a project initiated by Ministry of Education, Health Administration Department in 1994, in the first pilot schools girls and boys began to be taught "sexual education" course in separate classes, but this practice did not remain in force for a long time (Çalışandemir et al. 2008). In a study carried out by CETAD (2006) in seven regions, 20 cities with 1537 people, the question "Should sex education be given to boys and girls together or separately?" was replied as separately by $65.9 \%$ of the participants and together by $34.1 \%$. Unlike our study Kumcağız et al. (2013) found out that $38.3 \%$ of the counselors wanted sexual health lessons in small groups consisting of girls and boys and likewise $38.3 \%$ of them wanted sexual health lessons in big groups consisting of girls and boys. These findings suggest that on nursing students' sexual attitudes and behaviors, ongoing effects of conventional structure fueled with gender discrimination and male-female differences still exist.

In our study, students said to have chosen sexual health course "to have information about sexual and reproductive health" and "to correct the wrong things they know to be correct". Similarly in a study examining the views of prospective psychology counselor on sexual health education by Kumcağız et al. (2013), 59.1\% of students said to have chosen sexual health course to obtain correct information'. Özcebe et al. (2007) determined that one out of four women and two out of four men among 2963 people aged 15-24 years old had no information about women's ovulation and they had insufficient knowledge about reproductive organ. Pinar et al. (2009) suggest that $81.9 \%$ of university students wanted to be given information about sexual health. To educate young people about sexual health will enable them act maturely and responsibly, make right choices and protect and improve sexual health in the community. 


\section{Conclusion}

It is understood that as in the other studies with university students, a large part of the undergraduate nursing program students also consult non-school resources about sexual matters, had insufficient knowledge, and chose the lesson to obtain information about sexual health reproduction and it met their expectations. The findings of this study suggest that a comprehensive sexual education in nursing education will play an important role in increasing students' proficiency and knowledge on this issue and meeting their information needs.

Informed Consent: Verbal informed consent was obtained from students who participated in this study

Peer-review: Externally peer-reviewed.

Author Contributions: Concept KYÇ; Design KYÇ; Supervision KYÇ, SA; Materials KYÇ, AP; Data Collection and/or Processing KYÇ, AP; Analysis and/or Interpretation KYÇ; Literature Review KYÇ, SA, RE; Writing KYÇ; Critical Review KYÇ,SA,RE.

Conflict of Interest: No conflict of interest was declared by the authors.

Financial Disclosure: The authors declared that this study hasn't received any financial support.

\section{References}

Alpua Z. The attitudes and behaviors of adolescents' parents and teachers about sexual and reproductive health. Diyarbakır: Dicle University Institute of Health Sciences. 2006.

Akbaş T. Perspectives of sexual education and teachers about sexual education. Adana: Çukurova University Faculty of Education Publications; 2000.

Atan Ünsal Ş, Duran Taşçı E, Şen S, Bolsoy N, Sevil Ü. University students' knowledge, views, practices about sexuality and family planning methods. Ege University Faculty of Nursing Journal 2012; 28: 13-25.

Aydoğan A. Marmara University explored: Turkish youth does not know sexuality. 2001. Availablefrom:URL:http://www.milliyet.com/2001/0 5/19/yasam/yas03b.html on 12/01/2014.
B1kmaz FH, Güler DS. An evaluation of health and sexuality education in Turkish elemantary school curricula. Sex Education 2007; 7: 277292.

Blum RW, Nelson MR. The health of young people in a global context. J Adolescent Health 2004; 35: 402-418.

Biri A, Korucuoğlu Ü, Yilmaz E, Şimşek Ç, Aksakal N, İlhan M. Identifying the information needs of adolescent girls. Turkish Obstetrics and Gynecology Journal 2007; 4: 104-107.

Bozdemir N, Özcan S. A general overview on sexuality and sexual health. Turkish Journal of Family Medicine and Primary Care 2011; 5:3744.

CETAD. From Sexual Education, Treatment and Research Association "Sexual life and its problems in the area of sexual and reproductive health advocacy project through national and local media, Data File 1. 2006, İstanbul. Available from: Erişim adresi: URL: www.cetad.org.tr/.../2692011151611-

bilgilendirme_dosyasi_1.pdf

CETAD. From Sexual Education, Treatment and Research Association "Youth and Sexuality" file, the issues that young people talk least but are worried most: Sexuality. 8. Informing file pres release. 8 Mayis 2007, İstanbul. Available from: URL: www.cetad.org.tr/../269201116846abilgilendirme_dosyasi_7.pdf

Civil B, Yıldı H. Male students' sexual experiences and views towards sexual taboos in society '. Dokuz Eylül University School of Nursing Journal, Electronic Journal 2010; 3: 58-64.

Çalışandemir F, Bencik S, Artan İ. Children' sexual education: an overview from past to present. Education and Science 2008; 33: 1427.

Cetin S, Bildik T, Erermiș S, Demiral N, Özbaran B, Tamar M, Aydın C. Male adolescent's sexual behavior and sexual information sources: an evaluation after eight years recess. Turkish Psychiatry Journal of 2008; 19: 390-397.

Çok F, Kutlu Ö. A program attempting to give sexual education to adolescent. First edition. Ankara: Pegem Publisher; 2010.

Dağ H, Dönmez S, Kavlak O, Şirin A. University youth reproductive and sexual health knowledge and peer education. Anatolian Journal of Nursing and Health Sciences 2012; 15: $10-17$. 
Erbil N, Orak E, Bektaş AE. What do mothers know about sexual education and how much do they give sexual education to their daughters? International Journal of Human Sciences 2010; 7: 366-383.

Esgin A. Youth and sexuality: attitudes and behaviors of young people towards sexuality. Sivas: Cumhuriyet University Social Sciences Institute. 2000.

Gökengin D, Yamazhan T, Özkaya D, Aytuğ S, Ertem E, Ara B, Serter D. Sexual knowledge, attitudes and risk behaviors of students in Turkey. The Journal of School Health 2003; 73: 258-263.

Gölbaşı Z. Reproductive health problems and affecting factors in adolescent period. Ataturk University School of Nursing Journal 2005; 8: 100-108.

Güler S, Yöntem Deniz Z. The effect of group guidance activities regarding adolescence and sexual health education on knowledge and attitudes of 6th graders. Elementary Online Magazine 2007; 6: 2-10. (Accessed: 30.11.2014).

Gürsoy E, Gençalp NS. The Importance of Sexual Health Education. Family and Society 2010; October-November-December: 29-36.

Hazır BF, Güler DS. An evaluation of health and sexuality education in Turkish elementary school curricula. Sex Education 2007;7: 277292.

HÜKSAM. Hacettepe University The project of investigating the factors affecting adolescent and youth sexual/ reproductive health at Research and Application Centre of Women Issues. 2002, Ankara. Available from: URL: www.huksam.hacettepe.edu.tr/Turkce/Projeler_ pro.php

Kadıoğlu H, Yıldız A, Ercan N, Ergun A. University students' views on sexuality and sexual education. Ongoing Medical Education Journal 2008; 17: 32-37.

Karabulutlu Ö, K1lıç M. Determining the level of knowledge about sexual and reproductive health of university students. Journal of Anatolian Nursing and Health Sciences 2011;14: 39-45.

Kumcağız H, Çelik SB, Baru Y, Koçyiğit M. Prospective Psychological Counselor's Feedback on the Sexual Health Education Course. Journal of Kurşehir Education Faculty 2013: 14: 227-242.
Nalbant H. Bulut A. Gençler ve Üreme Sağlığı. Aktüel Tıp Dergisi 2001; 6 (1):30-36.

Nicoll A, Catchpole M, Cliffe S, Hughes G, Simms I, Thomas D. Sexual health of teenagers in England and Wales; analysis of national data. BM, 1999; 318: 1321-1322.

Özcebe H, Ünalan T, Türkyılmaz S, Coşkun Y. 2007 Turkey Youth Sexual and Reproductive Health Survey. First Edition. Demography Society Publication: Ankara; 2007.

Pınar G, Doğan N, Ökdem Ş, Algie, L, Öksüz E. Sexual health attitudes and behaviors of the students studying at a private university. Medical Research Journal 2009; 7: 105-113.

Siyez MD. Investigating the knowledge and the attitudes of primary school fourth grade students about puberty and sexual health. Contemporary Education Journal 2009; 34: 1726.

Tokuç B, Berberoğlu U, Saraçoğlu GV, Çelikkalp Ü. Views of Health Sciences School students about extramarital sex, abortion, induced abortion and contraceptives. Turkish Public Health Journal 2011; 9: 166-173.

Topkaya N, Sümer ZH. Sexual information sources, competence perceptions, and information needs of psychological counselor and guidance students. Turkish Psychological Counseling and Guidance Journal 2010; 4:139148. 